\title{
Research on Harmonized Human-Computer Interaction Design for Preschool Education for Children
}

\author{
Chen Qing Ling;Wang Yan Jun \\ Fuzhou University \\ Amoy Institute of Arts and Crafts, Fuzhou University, 852 Ligong Road, Jimei District \\ Amoy,Fujian China \\ Phone+861367518240 E-mail 473307029@qq.com
}

\begin{abstract}
How to effectively construct a preschool education method for children with good emotional interaction and human-com puter interaction, and to raise children's cognitive ability, beh avior habits, and establish a correct outlook on life through hu man-computer interaction is a matter of rapid development of information technology. problem. Through the analysis of the harmonious human-computer interaction design in children's preschool education tools, this paper proposes a research on $h$ uman-computer interaction mode for children's preschool edu cation, which will provide a more effective and harmonious $h$ uman-computer interaction mode for children's preschool edu cation.
\end{abstract}

Key words:Preschool education;Human interaction;Harmoni zation.

The human-computer interaction (HCI) has been with us since the emergence of computer in 1964.In recent years, the application of $\mathrm{HCI}$ has got great improvement . And HCI-design has been

utilized in various aspects of our daily life including preschool education for children. Based on the software of preschool education in App store, this paper links the harmonized HCI -design with children's concentration training and discusses about the application of HCI in visual sense, auditory sense and tactile sense.

\section{A.Research Background}

Preschool education is the significant beginning of life-lon g education system, therefore, the educational product and ins tructional resources for preschool education will have great in fluence on physical and mental development of children. Pres chool education system is designed to promote physical and mental development of preschool children. The preschool edu cation and children's development is interrelated and mutuall y restricted.

The preschool stage of children is a significant stage in our lifetime. Many basic abilities are formed in this stage, such as language expression, thinking mode, social communication a bility etc. It is also a critical period for the rapid development of children's nervous system. Preschool education plays an im portant role in formation of children's intelligence, emotion an $\mathrm{d}$ logical sense. The enhancement of education quality is of $\mathrm{g}$ reat significance to cultivate good habits and improve moral $\mathrm{c}$ ultivation for child. On the other hand, proper preschool educ ation guide children to cultivate good behavior habits and outl ook on life

In the program and interface system, the consistency of con cept semantics, patterns, syntax of command language 60 and display format should be required. The consistency of huma $\mathrm{n}$-computer interaction and harmonic design is mainly reflecte $\mathrm{d}$ in the consistency of input and output styles. The first interf ace and the second interface have similar layout, similar huma $\mathrm{n}$-computer interaction and similar information display format s.

The design of human-computer interaction interface should first establish the type of user, that is, predict their different re sponses to the interaction interface according to the characteri stics of different users. This will be analyzed from various as pects of design. For example, the interaction interface for fe male users is generally designed to be gentle and elegant. Th e interface for male users is generally designed to be stable an d deep.

Let the computer do more work, reduce the user's work as much as possible, and let the user use some shortcut keys inst ead of some tedious commands.

The communication of information is the basis of human-c omputer interaction, and the harmonious design of human-co mputer interaction is to replace complicated information with simple symbols or languages in many information exchanges, reduce the memory burden of users and adopt a design schem e that is conducive to memory.

The interactive interface should be able to respond to the us er's operation commands in time to help the user deal with pra ctical problems. In some important operations, there is an int erface reminder to give the initiative to the user as much as po ssible.

The success of interaction design is not only to provide rich media resources to users, but also to deal with various media integration relationships and make human-computer interactio $\mathrm{n}$ more natural. Human - computer interaction design in front of the goal focuses on people-oriented so that the interaction design conforms to these habits and patterns. To achieve intel ligent human-computer interaction.

Nowadays, human-machine operation is mostly realized thr ough command input and icon clicking, including the develop ment of touch screen technology. However, these modes of o peration do not eliminate the gap between man and machine. Computers are an extension of human functions, but people ar e tired of the operation of mice and keyboards and yearn for a more natural mode of operation, just like using a part of their own body. With the development of intelligent technology, $p$ 
eople have continuously improved the interactive design, and can now implement real-time operation on the $3 \mathrm{D}$ virtual reali ty environment through virtual input devices such as data clot hing, 3D mouse, data gloves, eye tracking, voice input, etc. T he tedious keyboard input or mouse click operation is omitted, and human beings can operate the machine more easily and $n$ aturally.

With the development of Internet market, there are an incre asing number of intellectual products for preschool children. I nstead of traditional education method such as picture books a nd Intelligent toy, parents prefer to choose some new ways $\mathrm{w}$ ith the Internet, pad and mobile phone, which bring unpreced ented change for preschool education.

\section{$B$. The current development of HCI-design for the preschool}

\section{education field}

The best results will be obtained if your computer word-processor has several font sizes. Table I recommends all the font sizes for your reference. As an aid to gauging font size, 1 point is about $0.35 \mathrm{~mm}$. Use a proportional, serif font such as Times or Dutch Roman.

With the development and innovation of information techn ology, HCI- design is constantly updated. The purpose of HCI -design is to enable the users to operate in a relaxed atmosphe re. In recent years, HCI is an anthropomorphic design of co mputer system, which is represented by multi-channel and mu ltimedia intelligent technology. The invitation of pad makes HCI product miniaturized as well as portable and makes oper ation easier. When the one-dimensional information space tra nsfers into multi-dimensional mode, HCI realizes the humancentered interactive mode, which makes the computer recogni ze and analyze the information with language, picture, text, ge sture and facial expressions. With the improvement of HCI a pplication, HCI-design has been utilized in various aspects o f our daily life including preschool education for children.

Simple games are often found in preschool education softw are. In the past decade, the upgrade of preschool education sof tware can't keep up with the development of science and tech nology. Targeted training enables to promote rapid change of cerebral cortex and children's concentration, therefore, it is $n$ ecessary to perfect preschool education software especially th ose designed for improving children's cognitive ability.

In App store, the number of Apps for children education inc reases to more than 5000 by March, 2018, including 793 fivestar Apps, 1342 four-star, 1455 three-star,1475 two-star and . 326 one-star, as in (TABLE I).

TABLE I

THE NUMBER OF APPS FOR CHILDREN EDUCATION INCREASES

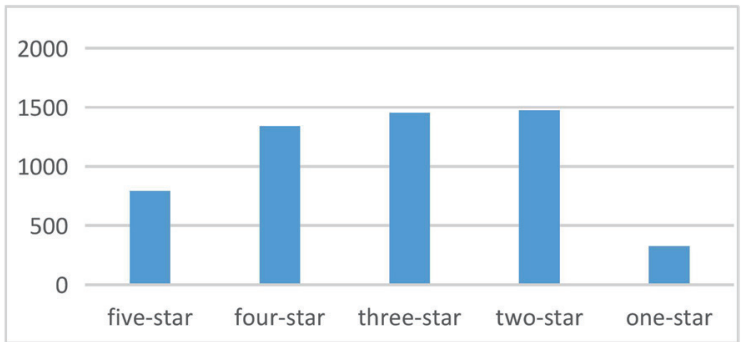

From the data, we can find that the number of the highest-r anked software is smaller than those in lower ranks. This data analysis shows deficiency of popular Apps for children educat ion. In App store, more than $80 \%$ best selling educational Ap ps are designed for children. This paper classifies children ed ucation software into language category, intelligence category, game category, music\&dance category, etc. In App store, the most two popular categories are language and game.

\section{How to Apply Concentration and Visual-Auditory Design to $\mathrm{HCI}$}

Concentration refers to the ability of one's mental activity $t$ $\mathrm{o}$ focus attention on something. The ability of concentration $\mathrm{c}$ ontrolling is the fundamental partof cognitive activities, and c hildren's concentration -formation is an important part of pre school education.

Concentration is characterized by two elements, directiona lity and centrality.Directionality refers to giving focused atten tion to specific, chosen detail in our surroundings. Centrality $r$ efers to the emotional tension and intension when concentrat ed on something. The emergence and duration of concentratio $\mathrm{n}$ depends on the external stimulus and subjective factors. As the research result of neuroplasticity shows, our cognition su ch as the ability to control concentration and working memor y capacity is expected to trained and strengthened by new tec hnology, audio-visual interaction, haptic interaction and trans cranial, electromagnetic stimulation and brain-computer interf ace.

Concentration is the mental activity directing to and focusi ng on the specific object, and concentration is an influencing $f$ actor for some other psychological process, such as perceptio $\mathrm{n}$, imagine and memory . The development of one's concentra tion has impact on the intellectual development. With percepti on, children have a elementary understanding of the world an $\mathrm{d}$ know more new things, therefore, we can make full use of $\mathrm{c}$ hildren's curiosity to cultivate their concentration.

It exemplifies that those objects attracting children's attenti on tend to be constantly changing and interesting, for instanc $\mathrm{e}$, the singing birthday cake, the jumping frog and the walking doll. These objects arouse children's curiosity and draw their attention to observe. Therefore, it is necessary to apply sense of vision and auditory sense to the interfacial design of child education software.

The research of man-computer engineering finds out that 8 $0 \%$ of the information receiving from the outside world depen ds on sense of vision and the others are auditory and tactile s ense. The visual and auditory sense plays an important role $\mathrm{w}$ hen learning. Compared with traditional learning methods like books and pictures, the interactivity of software for children education is irreplaceable. The interactivity of software enabl es the emergence of customized learning service with animati on, sound, picture, which can not be realized by printed book s.

Interaction design makes human-computer interaction appe ar blood, flesh and character, and also makes the interaction $\mathrm{i}$ nterface and user have emotional interaction. The performanc e made by grasping the emotional scene of the target user mat ches the user's mood very well, and enables the user to take th e initiative to stand on the user's side through computer intera ction, thus resolving the uncomfortable feelings that the user may have.

Excellent human-computer interaction design should have a simple operation, beautification and accurate interface, and 
pay more attention to the safety and reliability of interaction. When people operate the machine, they often make irreparabl e mistakes due to lack of experience, inattention, misjudgmen $\mathrm{t}$, etc. For example, if the function is deleted improperly, info rmation will be lost. The development of intelligent technolo gy has minimized such mistakes and created a safer, more reli able and more efficient man-machine interaction.

In recent years, the HCI is an anthropomorphic design of a computer system, which is represented by multi-channel and multimedia intelligent technology. The invitation of pad mak es HCI product miniaturized and portable. Simple operation $p$ rocedure, beautified user interface and security guarantees ar e indispensable for an excellent HCI-design.

In recent years, emotional design is one of the methods hav ing been considered in the design industry to enable to better handle the relationship between people and objects. Emotiona 1 Design emphasizes emotional experience more than usabilit y and accessibility. Donald Arthur Norman known as an Ame rican cognitive scientist and psychologist classifies emotional design by three levels, visceral level, behavioral level and refl ective level.

\section{D.Discussion on optimizing HCI design for preschool education software}

Preschool children in the preschool stage depends on the fi gurative thinking, because their ability of abstract thinking is not well-developed. The cognition level and preference of use rs should be taken into consideration for the software design., with which, the software designers can create sound learning environment and situation to arouse children ${ }^{\circ} \mathrm{s}$ interest in lea rning.

From the perspective of education, early education is aimed at preschool children aged from 0 to 6 years old, so as to bett er develop their intelligence by satisfying all kinds of stimuli $r$ equired during their brain development. The content of formal early education is designed according to the law of human co gnitive development, which is a kind of training rather than $\mathrm{k}$ nowledge learning.

From the perspective of cognitive ability (that is, the more $f$ ocused learning ability in early education), the classic piaget $\mathrm{c}$ ognitive development stage in developmental psychology is $\mathrm{s}$ ummarized as follows:

Sensory motor stage from 0 to 2 years old. Includes: repetit ion action, schema, mental representation, symbolic thinking

This period of baby in coordinating the senses, more like th e bright color, moving objects, and music. They constantly re peat are interested in and love, to establish contact with the ou tside world gradually, the resulting target behavior and expect ed (for example, will pass pull on the rope toys), and have the mental representation or symbolic thinking ability. In this per iod, the most important thing for children is to contact, imitate and explore more, instead of putting pressure on education to o early.

The pre-operational stage is 2-6 years old. Including: symbol representation system

Children in this period began to have the concepts of "sym bol" and "representation", with simple thoughts, concepts and reasoning, and liked symbolic games (such as playing house). But their minds remain single-dimensional, self-centered and incapable of understanding complex abstractions. In this peri od, learning mathematics and other things, such as role-playin g games to exercise children's symbolic ability.

After the age of 7, they liked slow things, they couldn't tell fantasy from reality, and they began to recognize simple chara cters. The child begins to understand quantity relation and log ical relation reasoning, gradually learns concrete image gener alization, image abstract generalization, preliminary essence a bstract generalization (using xyz symbol), and finally forms al gebraic proposition generalization. That is to say, only after 7 years old can children acquire the operation concept and deve lop logical thinking ability. Therefore, education software for children should design interactive interface and course directi on according to the age of children.

It is common to add some instructive elements in situation design, and the elements help children to solve problems by $t$ hemselves and take the control of learning process. Meanwhil e, with imagine and experiment, we can recall the knowledge mastered before and reconnect old and new knowledge. Lifeli ke design, pop-up window and arrow button constantly accel erate the formation and development of learner ${ }^{*} \mathrm{~s}$ abstract thi nking, strengthen their memory and mastery of knowledge. It is natural instincts of children to love playing. So edutainment is important,which means allowing children to learn new kn owledge and skills with playfulness.

In digital times, learners show interesting in the course cont ent demonstrated with both pictures and texts by education so $\mathrm{ftware}$. Faced with massive amounts of information, learners $\mathrm{s}$ pend much time to filter critical information, and the massive information increase learners ${ }^{*}$ cognitive load. So children ${ }^{*} \mathrm{~s}$ cognitive level and age characteristic should be taken into ac count for children education software designing. The software is expected to be innovative and comprise new ideas, emotio nal design factors and comfortable user experience. The desig ner or developer emphasize learners ${ }^{\circ}$ cognitive level when se tting the course content.

Good mood makes high learning efficiency. With proper ev aluation, children will be in good mood and their confidence $i$ $n$ re-cognition will be enhanced. This system of evaluation ne eds to be set up for learning process as well as learning outco mes. The evaluation system aim to arouse children ${ }^{*} \mathrm{~s}$ interest in learning new things.

Self-centeredness is an important characteristic of children, therefore, with evaluative feedback during their learning proc ess, learners can check whether $t$ their opinion is correct and $t$ hen correct mistakes in time. Constructivism holds that the va lue of learning comes from one $\mathrm{s}$ experience. In other words, the education software designing needs to be linked with life experience, from which a thorough understanding of knowle dge comes from. Education software linking with life experie nce and catering to children ${ }^{*} \mathrm{~s}$ cognitive level will motivate $t$ hem to learn. Learning in relaxed atmosphere can enhance eff iciency and arouse interest in learning, so the education softw are is supposed to possess life-like learning environment and good learning resource.

\section{References}

[1] G. Eason, et al., Phil. Trans. Roy. Soc. London, A247, pp. 529-551, April 1955.

[2] J. Clerk Maxwell, A Treaties on Electricity and Magnetism, 3rd ed., Vol. 2, Oxford: Clarendon Press, 1892, pp. 68-73. 
Educational Innovations and Applications- Tijus, Meen, Chang ISBN: 978-981-14-2064-1

[3] I. S. Jacobs and C. P. Bean, Magnetism, 3, G. T. Rado and H. Suhl, Eds., New York: Academic Press, 1963, pp. 271-350.

[4] M. Smith, "Title of paper optional here," unpublished.

[5] K. Rose, "Title of paper with only first word capitalized," in press.

[6] Y. Yorozu, et al., IEEE Trans. J. Magn. Japan, 2, pp. 740-741, August 1987 [Digests 9th Annual conf. Magn. Japan, p. 3012, 1982] 